\title{
Prognostic value of E2F1 in rectal cancer
}

\author{
Hasan Uzer, Hızır Akyıldız, Erdoğan Sözüer, Alper Akcan, Bahadır Öz
}

\begin{tabular}{ll}
\hline ABSTRACT & $\begin{array}{l}\text { Objective: To evaluate whether E2F transcription factor } 1 \text { is a potential prognostic marker in patients with rectal } \\
\text { cancer. } \\
\text { Material and Methods: Eighty-two patients who were treated with curative resection because of rectal cancer in the } \\
\text { Erciyes University School of Medicine, Department of General Surgery were included in the study and analyzed retro- } \\
\text { spectively. Data were obtained from patient files, pathology reports, and hospital information system. Nuclear and } \\
\text { cytoplasmic staining of E2F transcription factor } 1 \text { was performed for immunohistochemical analysis on paraffin- } \\
\text { embedded and blocked tumor tissue samples of patients. The findings of the study were assessed with using IBM } \\
\text { Statistical Package for Social Sciences Statistics } 20 . \\
\text { Result: In the 5-year follow-up period, } 34 \text { (41.5\%) patients were alive. Local recurrence was identified in } 7 \text { patients. } \\
\text { According to E2F transcription factor } 1 \text { nuclear staining, the average survival rate in patients was } 60 \% \text { for strong } \\
\text { nuclear staining and } 28 \% \text { for weak nuclear staining. There was significant statistical difference between groups ac- } \\
\text { cording to their degree of nuclear staining ( } p=0.017) \text {. When the patients were evaluated according to cytoplasmic } \\
\text { staining with E2F transcription factor 1, the average overall survival rate of patients with positive E2F transcription } \\
\text { factor } 1 \text { cytoplasmic staining was } 48.0 \pm 4.6 \% \text { versus } 55.9 \pm 7.9 \% \text { for patients without staining ( } p=0.408) . \\
\text { Conclusion: The survival rates are higher in rectal cancer patients with strong immunohistochemical nuclear stain- } \\
\text { ing of E2F transcription factor } 1 .\end{array}$ \\
Keywords: Rectal cancer, E2F1, prognosis
\end{tabular}

Cite this paper as: Uzer H, Akyıldız H, Sözüer E, Akcan A, Öz B. Prognostic value of $\mathrm{E} 2 \mathrm{~F} 1$ in rectal cancer. Turk J Surg 2017; 33: 180-184

This study was presented at the $48^{\text {th }}$ Congress of European Society for Surgical Research. 29 May-1 June 2013, İstanbul, Turkey.

Department of General Surgery, Erciyes University School of Medicine, Kayseri, Turkey

Address for Correspondence Hızır Akyıldız e-mail:hyakyildiz@gmail.com

Received: 05.04 .2016 Accepted: 25.05.2016

CCopyright 2017 by Turkish Surgical Association www.turkis

\section{INTRODUCTION}

Colorectal cancers constitute approximately $10 \%$ of all cancer cases (1). Almost 1,000,000 patients are diagnosed with colorectal cancer worldwide each year, and almost 500,000 people die from this disease annually. Colorectal cancer is the third most common type of cancer in both sexes; it is the second most common cause of death due to cancer in men and the third most common cause of death due to cancer in women (2). Although developments in both the surgical and oncological treatment methods of patients with colorectal cancer make a positive contribution to the survival of patients, the lack of prognostic parameters to predict the effectiveness of treatment planning is still a major problem.

E2F transcription factor 1 (E2F1) is a transcription factor that both activates and suppresses many biological processes such as DNA replication, mitosis, DNA repair, differentiation, and autophagy. It can also trigger apoptosis $(3,4)$. Disruption of various parts of the pathway that controls the growth of E2F1 molecules leads to loss of control and the development of a variety of cancers (5-7). It has been shown that E2F1 plays a role in thyroid and non-small-cell lung carcinomas and the expression of E2F1 induces medulloblastoma, glioma and lung, colon, and bladder cancers after treatment with adriamycin or etoposide (8-12). It was reported that E2F1 has a higher ratio of nuclear positivity and is associated with aggressive behavior in malignant gastrointestinal stromal tumors (13).

Additionally, E2F1 has been studied a prognostic marker in gastric, urothelial carcinoma of urinary bladder, and squamous cell carcinoma of the tongue; however, it has been not previously studied in rectal cancers (14-16). The purpose of this study was to investigate whether E2F1 is a potential prognostic marker in the diagnosis of rectal cancer patients who undergo curative surgery.

\section{MATERIAL AND METHODS}

After receiving ethical approval, the study was performed jointly by the Erciyes University School of Medicine, Department of Pathology. Eighty-two patients who were treated with curative resection due to rectal cancer at the Erciyes University School of Medicine, Department of General Surgery were included in the study. Informed consent was obtained from all patients before surgery. The names and 
surnames of the patients; hospital protocol numbers; age; gender; address; telephone number; and identifying information, such as data on demographic characteristics, dates of surgery, the operation and perioperative period information (such as local recurrence, tumor histological type, differentiation, tumor size, the number of lymph nodes affected, the involvement of local invasion, vascular invasion, perineural invasion, and positive surgical margins) were obtained from patient files, hospital information system, and pathology reports. The data were analyzed retrospectively.

The current condition of the surviving patients was determined according to the findings of the last follow-up. The final status of the population whose last follow-up date was more than 6 months before were investigated by telephone or from the population directorate. Staging was done according to the criteria of the American Joint Committee on Cancer (AJCC) 2010 staging of colon and rectal cancer. All tissue samples were taken from surgical excision materials. Paraffin-blocked tissue samples of patients were obtained from the archives of the Department of Pathology.

\section{Immunohistochemical Staining of E2F1}

Tissue sections of the 82 patients' formalin-fixed 5-6-micron paraffin blocks were transferred to poly-L-lysine coated slides for immunohistochemical studies. The tissue sections were deparaffinized with xylol after standing for an hour in the incubator and then dehydrated with alcohols in rising degree (4 times for $2 \mathrm{~min}$ ). Endogenous peroxidase activity was blocked with hydrogen peroxide. Tissues were heated with Ethylenediaminetetraacetic acid (EDTA) buffer in the microwave 3 times for $10 \mathrm{~min}$ and then allowed to cool for $5 \mathrm{~min}$. The tissues were washed with phosphate buffered saline (PBS). E2F1 antibody (Santa Cruz Biotechnology, USA, dilution 1:100, incubation time $30 \mathrm{~min}$ ) was added and allowed to stand in the refrigerator overnight. In the next step, the tissues were washed with tris-buffered saline (TBS, $\mathrm{pH}=7.4$ ). Antigen-antibody binding was made visible by being incubated with biotinylated antirabbit antibody, streptavidin, Avidin-Biotin Complex (ABC) with Horseradish Peroxidase (HRP) solution, and diaminobenzidine for $10 \mathrm{~min}$, in that order. They were counterstained with hematoxylin (Mayer). Then, the washed preparations were closed with a coverslip instilled with balsam.

\section{Immunohistochemical Evaluation of E2F1}

For the positive control, internal staining of the tissue was evaluated for immunohistochemical staining. Tonsil tissue was used as a positive control. For the nuclear staining of E2F1, 500 cells were counted under $10 \times$ magnification and were classified as mild, moderate, and severe according to the severity of staining (Figure 1).

\section{Statistical Analysis}

Data were evaluated with the IBM Statistical Package for the Social Sciences 20 statistical package program (IBM Corp.; Armonk, NY, USA). The mean, percentage, and standard deviation were given as descriptive statistics. Quantitative variables were compared with the normal distribution of the ShapiroWilk test. Comparisons between groups according to the normality of variables were done with Student's t-test and Kruskal-Wallis tests. The exact method of the Chi-square test was used to compare categorical variables. Disease-free and over- all survival were assessed using Kaplan-Meier survival analysis and the log-rank test. To determine the factors that influence disease-free and overall survival, Cox regression analysis was used. A p value of $<0.05$ was considered statistically significant.

\section{RESULTS}

Fifty-three patients (64.6\%) were male and 29 (35.4\%) were female. The mean age was $68.1 \pm 1.5$ years and the median age was 69 (33-82). The histopathological features of the patients are shown in Table 1 and the surgical methods are shown in Table 2.

In terms of nuclear immunohistochemical staining of E2F1, 7 cases (8.5\%) showed strong staining, 17 cases (20.7\%) showed weak staining, and 58 cases $(70.7 \%)$ showed no staining. When the same cases were evaluated according to whether they

\begin{tabular}{|c|c|c|}
\hline Histology & $\mathrm{N}$ & $\%$ \\
\hline Adenocarcinoma & 79 & 96.3 \\
\hline Other & 3 & 3.7 \\
\hline \multicolumn{3}{|l|}{ Invasion } \\
\hline Serosa & 53 & 64.6 \\
\hline M. Propria & 21 & 25.6 \\
\hline Subserosa & 4 & 4.9 \\
\hline Adipose Tissue & 2 & 2.5 \\
\hline Mucosa & 1 & 1.2 \\
\hline Submucosa & 1 & 1.2 \\
\hline
\end{tabular}

\section{Vascular Invasion}

$\begin{array}{lll}\text { Yes } & 25 & 30.4\end{array}$

No

57

69.6

\section{Perineural Invasion}

Yes

$18 \quad 22$

No

64

78

\section{Surgical Margin}

$\begin{array}{lcc}\text { Positive } & 3 & 3.6 \\ \text { Negative } & 79 & 96.4\end{array}$

Lymph Node Metastasis

Yes

40.2

No

49

59.8

Table 2. The surgical methods

\begin{tabular}{|lcc|}
\hline & N & \% \\
\hline LAR & 32 & 39 \\
\hline APR & 29 & 35.4 \\
\hline Anterior Resection & 17 & 20.7 \\
\hline Total Colectomy & 4 & 4.9 \\
\hline Total & $\mathrm{N}=82$ & \\
\hline
\end{tabular}

LAR: low anterior resection; APR: abdominoperineal resection 
were stained or unstained, 24 cases (29.3\%) were stained and $58(70.7 \%)$ were unstained.

In terms of cytoplasmic immunohistochemical staining of E2F1, it was observed that 11 cases (13.4\%) were strongly stained, 28 (34.1\%) were moderately stained, 19 (23.2\%) were weakly stained, and $24(29.3 \%)$ were unstained. When the same patients were grouped according to whether there was staining or not, 58 cases (70.7\%) were stained and 24 cases (29.3\%) were unstained. In a 5-year follow-up, 34 patients (41.5\%) were alive and 7 (0.9\%) patients had local recurrence. The average 5-year survival was $43.7 \pm 3.4$ months.

Survival rates were compared across different time periods depending on the staining of the nucleus. The mean survival time of the patients with nuclear staining with E2F1 and those without was 39\% and 55\%, respectively. The relationship between these results was statistically insignificant $(p=0.081)$. Relationship between E2F1 cytoplasmic staining and survival rates was also investigated. The average overall survival rate of the cases with E2F1 cytoplasmic staining

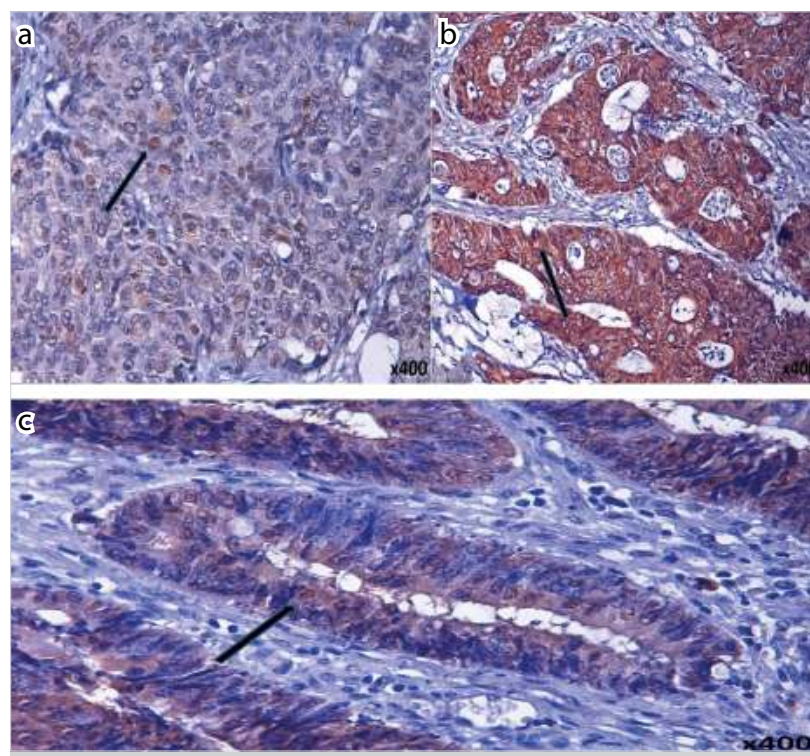

Figure 1. a-c. Immunohistochemical staining of E2F1. Magnification, x400. Nuclear (a), cytoplasmic (b), both nuclear and cytoplasmic staining of E2F1 (c) was $48 \%$ and that of cases without E2F1 cytoplasmic staining was $56 \%$. These differences were statistically insignificant $(p=0.408)$ (Table 3).

Survival was investigated according to the degree of nuclear staining: strong and weak nuclear staining. When two groups were compared according to their degree of staining, there was a significant difference between the group with strong nuclear staining and that with weak staining (Table 4)

When the patients were evaluated according to the stage and E2F1 nuclear staining, no significant difference was found between them $(p=0.212)$ (Table 5$)$. Similarly when the cases were classified according to the degree of nuclear staining (as stained weakly or strongly) and were compared with stage, no significant difference was found between the groups $(p=0.170)$. Patients were evaluated according to the stages in terms of E2F1 cytoplasmic staining and no statistically significant difference was found between the two groups ( $p=0.802)$. When the patients were classified according to the degree of cytoplasmic staining (as weak, medium, and strong stained) and were compared with the stages, there were no statistically significant results $(p=0.766)$.

Fourteen patients (17.1\%) received adjuvant chemoradiotherapy. There was no significant survival difference according to the nuclear staining degree in patients who received adjuvant chemoradiotherapy $(p=0.22)$.

The relationship of age, tumor size, nuclear and cytoplasmic staining with survival was evaluated by Cox regression analysis. There was no statistically significant difference between tumor diameter and cytoplasmic staining, but there was a statistically significant difference between age and severity of nuclear staining $(p=0.022)$. When the patients were evaluated according to the severity of nuclear staining, patients with a strong degree of nuclear staining had a 2.317-fold increase in the likelihood of survival compared with patients with a weak degree of nuclear staining.

\section{DISCUSSION}

One of the necessary steps in the treatment of the cancer is the development of molecular markers that help predict survival, potential behavior, and aggressiveness of the tumor. In

Table 3. Survival rates according to nuclear and cytoplasmic staining

\begin{tabular}{|c|c|c|c|c|c|c|c|}
\hline Staining & $\begin{array}{c}\text { 12-month } \\
\text { survival rate (\%) }\end{array}$ & $\begin{array}{c}\text { 24-month } \\
\text { survival rate (\%) }\end{array}$ & $\begin{array}{c}\text { 36-month } \\
\text { survival rate (\%) }\end{array}$ & $\begin{array}{l}\text { 48-month } \\
\text { survival rate (\%) }\end{array}$ & $\begin{array}{c}\text { 60-month } \\
\text { survival rate (\%) }\end{array}$ & $\begin{array}{c}\text { Mean } \\
(\%)\end{array}$ & $p$ \\
\hline Nuclear stained & 76 & 46 & 38 & 33 & 29 & 39 & 0.081 \\
\hline Nuclear unstained & 79 & 69 & 59 & 55 & 48 & 55 & \\
\hline Cytoplasmic staining & 79 & 60 & 50 & 47 & 38 & 48 & 0.408 \\
\hline
\end{tabular}

Table 4. Survival rates according to the degree of nuclear staining

\begin{tabular}{|lccr}
\hline $\begin{array}{l}\text { Degree of } \\
\text { nuclear staining }\end{array}$ & $\begin{array}{c}\text { 12-Month } \\
\text { survival rate (\%) }\end{array}$ & $\begin{array}{c}\text { 24-Month } \\
\text { survival rate (\%) }\end{array}$ & $\begin{array}{c}\text { 36-Month } \\
\text { survival rate (\%) }\end{array}$ \\
\hline Strong nuclear staining & 86 & 71 & 57 \\
Weak nuclear staining & 65 & 35 & 24 \\
\hline
\end{tabular}


Table 5. Analysis of patients according to the stage and E2F1 nuclear staining

Nuclear staining

\begin{tabular}{|lccc|} 
& Total $\mathbf{n}(\%)$ & Stained $\mathbf{n}(\%)$ & Unstained $\mathbf{n}(\%)$ \\
\hline Stage I & $10(12.2)$ & $2(20)$ & $8(80)$ \\
\hline Stage II & $34(41.5)$ & $7(20.6)$ & $27(79.6)$ \\
\hline Stage III & $26(31.7)$ & $9(34.6)$ & $17(65.4)$ \\
\hline Stage IV & $12(14.6)$ & $6(50)$ & $6(50)$ \\
\hline Total & $82(100)$ & $24(29)$ & $58(71)$ \\
\hline
\end{tabular}

the literature, several studies have been performed in recent years to address this deficiency (17-19). E2F1 is a transcription factor that has been studied in many tumor types, except for rectal tumors, for its prognostic value.

E2F transcription factor 1 has a role in the $\mathrm{G} 1 / \mathrm{S}$ phase transition of the cell cycle. In the transition of G1/S, Rb-E2F complexes are separated and E2F1 starts activating the transcription of many genes required for mitosis. The cyclin-dependent kinase-cyclin complex causes the separation of the Rb-E2F complex with Rb phosphorylation (20-22). P16 is a tumor suppressor gene product that prevents the creation of a complex between cyclin and cyclin-dependent kinase (23). Dong et al. (24) showed that E2F1 induces apoptosis in both normal and malignant cells. They also demonstrated that E2F1-dependent apoptosis could be independent of p53. Gene transfer to adenovirus with E2F1 is also effective in antitumor activity, with lower doses of chemotherapeutic agents (25). In the study of Xie et al. (26), E2F1 (+) plasmids were transfected into cells and it was shown that apoptosis increases, cell growth slows, and the cell cycle stops at the G2/M phase in gastric cancer. It is thought that E2F1 has a function as a tumor suppressor. La Belle et al. (5) investigated the role of E2F1 in programmed cell death. However, it has not been clearly elucidated if it works as an oncogene or a tumor suppressor. Bramis et al. (4) suggested that E2F1 was a tumor suppressor in colon cancer. Lee et al. (9) reported that in gastric cancer patients, the reactivity of E2F1 can predict overall survival rates independently.

In our study, when patients are grouped as E2F1 nuclear stained or not, the average survival of the E2F1 stained group is $39 \%$ and that of the unstained group is $55 \%$. These results were statistically insignificant $(p=0.081)$. If patients were evaluated according to their degree of nuclear staining, the median overall survival of cases with strong nuclear staining was $60 \%$ and that for those with weak nuclear staining was $28 \%$. There was a statistically significant difference between the groups according to their degree of nuclear staining $(p=0.017)$. These findings showed that the degree of staining is more decisive according to the presence of staining, for more influence, more E2F1 nuclear staining activity is necessary. The answer to the question why there is a significant difference in survival between strong staining and unstained groups remained to be elucidated with larger studies. When E2F1 cytoplasmic staining was evaluated, the average survival rate of the cytoplasmic staining-positive group was $48 \%$ and the average survival rate of the unstained group was 56\%. This difference was statistically insignificant $(p=0.408)$. It is suggested that the main effect of E2F1 is on the core. When the correlations between the stages of the disease and nuclear or cytoplasmic stainings were evaluated, any significant difference was not obtained according to both the intensity of the staining and staining alone. Because there was no correlation between E2F1 staining of either nucleus or the cytoplasm and the stages, we may assume that E2F1 plays a role independently from the stage, which means that in some tumors, tumor progression is not dependent on E2F1, whereas in some tumors, E2F1 plays a role from the beginning of the process. Further studies are certainly warranted to address this issue.

Cox regression analysis was used to evaluate the association of age, tumor diameter and cytoplasmic staining with survival. No statistically significant difference was found between tumor diameter and cytoplasmic staining, but the difference between age and degree of nuclear staining was statistically significant $(p=0.022)$. Patients with a strong degree of nuclear staining had a 2.3-fold increase in chances of survival compared with patients with weak staining $(p=0.010)$. These findings suggest that E2F1 does not stimulate cellular proliferation and differentiation but increases apoptosis in rectal cancer as in colon and prostate cancer.

\section{CONCLUSION}

As a result, E2F1 is effective, depending on the cell type and signals, and can act as an oncogene or tumor suppressor. It is found to be a poor prognostic parameter in lung, breast, esophageal, and pancreatic cancer, but it also has a protective effect by increasing apoptosis in colon, bladder, and prostate cancer.

Despite the relatively small number of cases, as the first study in the literature, our study demonstrated that E2F1 is a molecular marker that may predict the behavior and aggression of rectal cancer.

Ethics Committee Approval Ethics committee approval was received for this study from the ethics committee of Erciyes University.

Informed Consent: Written informed consent was obtained from patients who participated in this study.

Peer-review: Externally peer-reviewed.

Author Contributions: Concept - H.A.; Design - A.A.; Supervision - E.S.; Resource - B.Ö.; Materials - H.U.; Data Collection and/or Processing - H.U.; Analysis and/or Interpretation - H.U.; Literature Search - H.U.; Writing Manuscript - H.U.; Critical Reviews - H.A.

Conflict of Interest: No conflict of interest was declared by the authors.

Financial Disclosure: The authors declared that this study has received no financial support.

\section{REFERENCES}

1. Okyay P. Colorectal Cancer Epidemiology. Turkiye Klinikleri J Med Oncol 2013; 6: 1-5.

2. Siegel RL, Miller KD, Jemal A. CA. Cancer statistics Cancer J Clin 2015; 65: 5-29. [CrossRef]

3. Polager S, Ginsberg D. E2F - at the crossroads of life and death. Trends Cell Biol 2008; 18: 528-535. [CrossRef] 
4. Bramis J, Zacharatos P, Papaconstantinou I, Kotsinas A, Sigala F, Korkolis DP, et al. E2F-1 transcription factor immunoexpression is inversely associated with tumor growth in colon adenocarcinomas. Anticancer Res, 2004; 24: 3041-3047.

5. Bell LA, Ryan KM. Life and death decisions by E2F-1. Cell Death Differ 2004; 11: 137-142. [CrossRef]

6. Johnson DG, Schwarz JK, Cress WD, Nevins JR. Expression of transcription factor E2F1 induces quiescent cells to enter $S$ phase. Nature 1993; 365: 349-352. [CrossRef]

7. Helin K. Regulation of cell proliferation by the E2F transcription factors. Curr Opin Genet Dev 1998; 8: 28-35. [CrossRef]

8. Onda M, Nagai H, Yoshida A, Miyamoto S, Asaka S, Akaishi J, et al. Up-regulation of transcriptional factor E2F1 in papillary and anaplastic thyroid cancers. J Hum Genet 2004; 49: 312-318. [CrossRef]

9. Lee J, Park CK, Park JO, Lim T, Park YS, Lim HY, et al. Impact of E2F-1 expression on clinical outcome of gastric adenocarcinoma patients with adjuvant chemoradiation therapy. Clin Cancer Res 2008; 14: 82-88. [CrossRef]

10. Compton CC, Fielding LP, Burgart LJ, Conley B, Cooper HS, Hamilton SR, et al. Prognostic factors in colorectal cancer. College of American Pathologists Consensus Statement 1999. Arch Pathol Lab Med 2000; 124: 979-994.

11. Saiz AD, Olvera M, Rezk S, Florentine BA, McCourty A, Brynes RK. Immunohistochemical expression of cyclin D1, E2F-1, and Ki-67 in benign and malignant thyroid lesions. J Pathol 2002; 198: 157162. [CrossRef]

12. Gorgoulis VG, Zacharatos P, Mariatos G, Kotsinas A, Bouda M, Kletsas D, et al. Transcription factor E2F-1 acts as a growthpromoting factor and is associated with adverse prognosis in non-small cell lung carcinomas. J Pathol 2002; 198: 142-156. [CrossRef]

13. Sabah $M$, Cummins $R$, Leader $M$, Kay E. Altered expression of cell cycle regulatory proteins in gastrointestinal stromal tumors: markers with potential prognostic implications. Hum Pathol 2006; 37: 648-655. [CrossRef]

14. Liang YX1, Lu JM1, Mo RJ1, He HC1, Xie J1, Jiang FN, et al. E2F1 promotes tumor cell invasion and migration through regulating CD147 in prostate cancer. Int J Oncol. 2016; 48: 1650-1658. [CrossRef]
15. Rabbani F, Richon VM, Orlow I, Lu ML, Drobnjak M, Dudas M, et al. Prognostic significance of transcription factor E2F-1 in bladder cancer: genotypic and phenotypic characterization. J Natl Cancer Inst 1999; 91: 874-881. [CrossRef]

16. Kwong RA, Nguyen TV, Bova RJ, Kench JG, Cole IE, Musgrove EA, et al Overexpression of E2F-1 is associated with increased disease-free survival in squamous cell carcinoma of the anterior tongue. Clin Cancer Res 2003; 9: 3705-3711.

17. Park YJ, Park KJ, Park JG, Lee KU, Choe KJ, Kim JP. Prognostic factors in 2230 Korean colorectal cancer patients: analysis of consecutively operated cases. World J Surg 1999; 23: 721-726. [CrossRef]

18. Steinberg SM, Barkin JS, Kaplan RS, Stablein DM. Prognostic indicators of colon tumors. The Gastrointestinal Tumor Study Group experience. Cancer 1986; 57: 1866-1870. [CrossRef]

19. Dickman PW, Hakulinen T, Luostarinen T, Pukkala E, Sankila R, Söderman B, et al. Survival of cancer patients in Finland 1955-1994. Acta Oncol 1999; 38: 100-103. [CrossRef]

20. Stevens C, Smith L, La Thangue NB. Chk2 activates E2F-1 in response to DNA damage. Nature Cell Biol 2003; 5: 401-409. [CrossRef]

21. Sage J, Mulligan GJ, Attardi LD, Miller A, Chen S, Williams B, et al. Targeted disruption of the three Rb-related genes leads to loss of G1control and immortalization. Genes Dev 2000; 14: 3037-3050. [CrossRef]

22. Wu X, Levine A J. p53 and E2F-1 cooperate to mediate apoptosis. Proc Natl Acad Sci USA 1994; 91: 3602-3606. [CrossRef]

23. Haller F, Gunawan B, von Heydebreck A, Schwager S, Schulten HJ, Wolf-Salgó J, et al. Prognostic role of E2F1 and members of the CDKN2A network in gastrointestinal stromal tumors. Clin Cancer Res 2005; 11: 6589-6597. [CrossRef]

24. Dong YB, Yang HL, Elliott MJ, Liu TJ, Stilwell A, Atienza C, et al. Adenovirus-mediated E2F-1 gene transfer efficiently induces apoptosis in melanoma cells. Cancer 1999; 86: 2021-2033. [CrossRef]

25. Dong YB, Yang HL, McMasters KM. E2F-1 overexpression sensitizes colorectal cancer cells to camptothecin. Cancer Gene Ther 2003; 10: 168-178. [CrossRef]

26. Xie $Y$, Yin $Y$, Li L, Ma Y, Xiao Q. Short interfering RNA directed against the E2F-1 gene suppressing gastric cancer progression in vitro. Oncol Rep 2009; 21: 1345-1353. [CrossRef] 